\title{
Abcès Prostatique: About a Case
}

\author{
Walid Bai, Mehdi Graiouid, Mohamed Dakir, Adil Debbagh, and Rachid Aboutaieb
}

\begin{abstract}
We report the case of a prostate abscess in a diabetic and hypertensive patient followed for benign prostatic hypertrophy. The treatment consisted on the evacuation of the abscess by transrectal puncture associated with targeted antibiotic therapy.
\end{abstract}

Index Terms - Abcès, prostate, drainage.

\section{INTRODUCTION}

Prostatic abscess is a localized collection of purulent fluid in the prostate, often as a complication of prostatitis. It is a rare condition, its incidence is decreasing thanks to the wide and early use of antibiotics in urinary tract infections. It occurs on immunodeficiency grounds such as diabetes, chronic renal failure (CRF), or any other situation of immunosuppression. The contamination of the prostate is mainly ascending after an endoscopic maneuver; but it can also be done directly by a prostate biopsy. Often the clinical diagnosis is difficult because the signs are non specific compared to other prostatic infections. The easy and sometimes inappropriate use of antibiotics often leads to a delay in diagnosis (1). This diagnosis is made easy thanks to the endorectal ultrasound which occupies the main place in the diagnosis. The treatment relies on the adapted antibiotherapy and on the percutaneous drainage by transperineal, transrectal or endoscopic way.

\section{OBSERVATION}

A 68-year-old patient with a history of high blood pressure and poorly balanced type 2 diabetes was admitted to the emergency room with fever at $40^{\circ} \mathrm{C}$ for 48 hours with symptoms of low urinary tract complicated with acute urine retention . During the examination, we found slight edema of the scrotum, perineal sensibility and after rectal examination, a soft zone was palpated at the right lobe of the prostate, evoking an abscess. The patient was derived by catheter above pubis bringing back turbid urine with bacteriological sampling.

Blood tests showed predominantly PNN leukocytosis, inflammatory syndrome, and plasma creatinine at $21 \mathrm{mg} /$ dL. The urinary cytobacteriological examination showed significant leukocyturia (greater than 1,000,000) but the urine remained sterile. Treatment with ciprofloxacin injectable with gentamycin has been prescribed.

Endorectal ultrasonography found an intraprostatic hypoechoic mass on the right side measuring $28 \mathrm{~mm}$ in diameter suggestive of abscess (image 1). Puncture of this transrectal formation allowed drainage of $80 \mathrm{~mL}$ of pus in which a multisensitive

E. coli was found and treatment

Published on November 29, 2019 with ciprofloxacin was maintained. Under this wellmonitored treatment, the evolution was favorable. An ultrasound of control made 6 weeks after showed a disappearance of the abscess.

\section{DISCUSSION}

Prostatic abscess is a rare condition accounting for about $0.5 \%$ of all prostatic pathologies (2). It can affect men at any age (3) but most often it is patients in the 5th and 6th decades of life. It usually follows an acute prostatitis not or poorly treated often with a facilitating ground (diabetes, bladder catheterization, chronic renal failure, prostate abnormality).

Before the advent of modern antibiotic therapy, $75 \%$ of prostate abscesses were attributable to Neisseria gonorrhea, and the mortality rate was between $6 \%$ and $30 \%$ (4). Currently, Enterobacteriaceae, especially E. coli, are the main pathogens in acute bacterial prostatitis, with a decrease in incidence and improved prognosis.

Clinical signs are not specific and may be encountered in many other urological conditions (5). Pollakiuria, dysuria, and fever are the most common signs. Acute retention of urine and perineal pain are possible.

The most typical sign of prostate abscessis a very sensitive prostate with areas of fluctuation on the rectal examination but it is found only in 16 to $20 \%$ of cases. The prostate remains sensitive in $35 \%$ of cases (4).

Trans-rectal ultrasound (TRUS) The diagnostic method of choice, which also serves as a treatment and monitoring tool for patients with prostate abscess, transrectal ultrasound of the prostate It shows a hypoechoic zone at the beginning and which becomes frankly transonic at the collection stage with often posterior reinforcement (7). The scanner can be used but it is rather reserved to specify a possible extra-prostatic extension of the infectious phenomenon because the study of the pelvis is often of better quality (8).

Prostatic abscess treatment is based on antibiotic therapy and drainage. The initial probabilistic antibiotic treatment must be active on Gram-negative bacilli and with good intraprostatic penetration. Ciprofloxacin, which diffuses well in prostatic tissue and secretions, is the most commonly used first-line agent. It may be initially associated with an aminoglycoside that increases the rate of bactericide. This antibiotic treatment is secondarily adapted by favoring among the active antibiotics those with the best diffusion in the prostate, the combination trimethoprimsulfamethoxazole and fluoroquinolones (9). It must be extended for several weeks.

The derivation of urine by suprapubic catheterization is indicated in case of retention urine or discomfort. The drainage of the abscess can be transurethral, transrectal or transpereal (surgical or percutaneous). There are not many references to this pathology in the literature. Most series 
have been reported by Collado et al (10) who published a study of 31 patients with prostate abscess; Transrectal drainage was performed in 23 patients and 1 transperineal. In 5 of the patients drainage was achieved by transurethral resection of the prostate. And no drainage was performed in 2 patients. An antibiotic treatment was set up for all patients before the puncture so drainage was considered simple and safe technique that could be repeated if necessary. Gögus and Al. (5) published a series of 6 patients with prostate abscess, in which transrectal drainage was successfully completed in $83.3 \%$ of cases and recurrence in only 1 patient occurred after 3 weeks.

\section{CONCLUSION}

Prostatic abscess is a rare condition whose clinical symptomatology is not always specific In the post-antibiotic era, PA has evolved from a disease of sexually active young men to one of weakened and immunocompromised men. Transrectal ultrasound and CT are valuable imaging modalities in the diagnosis of prostate abscess as well as treatment. Broad-spectrum antibiotics associated with a procedure such as transurethral resection or echoged aspiration are the mainstays of treatment resulting in complete remission in the majority of patients.

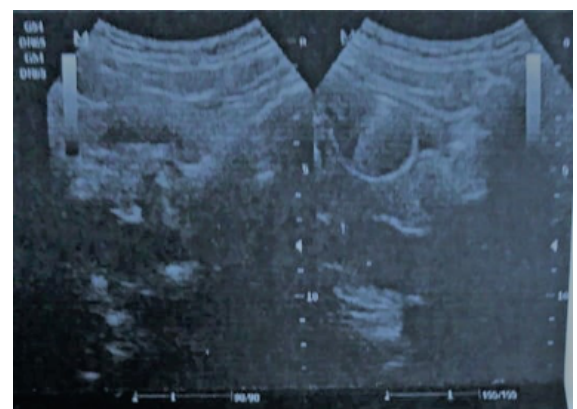

Fig. 1. Endorectal ultrasonography showing an intraprostatic hypoechoic mass on the right side, $28 \mathrm{~mm}$ in diameter, suggestive of abscess

\section{REFERENCES}

[1] Kadmon D, Ling D, Lee JkT. Percutaneous drainage of prostatic abscesses. J Urol $1986 ; 135$ : 1259-60.

[2] El Harrech Y, Chafiki J, Janane A, Ghadouane M, Ameur A, Abbar M. Aspiration échoguidée transrectale des abcès prostatiques. J. radiol. $2010 ; 91(2): 227-229$.

[3] Bhagat SK, Kekre NS, Gopalakrishnan G, Balaji V, Mathews MS. Changing profile of prostatic abscess. Int Braz J Urol 2008; 34:16470.

[4] Barozzi L, Pavlica P, Menchi I, De Matteis M, Canepari M. Prostatic abscess: diagnosis and treatment. AJR Am JRoentgenol. 1998; 170:753-7.

[5] Weinberger M, Cytron S, Servadio C, Block C, Rosenfeld JB, Pitlik SD. Prostatic abscess in the antibiotic era. Rev Infect Dis $1988 ; 10$ : 239-49.

[6] Dakir M, Aboutaieb R, Dahami Z, Sarf I, Zamiati W, Essakalli N, et coll. L'abcès prostatique à propos de deux cas. Prog. Urol. 2000; 10: 300-302.

[7] David M. Flores, Katie S. Murray, Tomas L. Griebling, Joshua A. Broghammer. Transrectal Ultrasound Guided Needle Aspiration of a Prostatic Abscess: Salvage Treatment After Failed Transurethral Resection Urology Case Reports 3 (2015) 101e102

[8] Barozzi L, Pavlica P, Menchi I, De Matteis M, CaneparicM. Prostatic abscess: diagnosis and treatment. AJR Am JRoentgenol. 1998;170:753-757.

[9] 1A.Saouli1O.Yddoussalah1A.Janane2T.Karmouni1M.Alami2A.Ameu r2K. ElKhader1A.Koutani1A. Iben AttyaAndaloussi1. African Journal of Urology Volume 24, Issue 4, December 2018, Pages 392394

[10] Jacobsen JD, Kvist E. Prostatic abscess. A review of literature and a presentation of 5 cases. Scand J Urol Nephrol 1993 ; 27 : 281-4. 